\title{
Antidiabetic and antiulcerative potential of Garcinia lanceifolia Roxb. bark
}

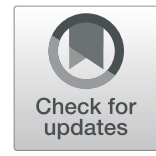

Nilutpal Sharma Bora ${ }^{1,2^{*}}$ (D) Partha Sarathi Bairy ${ }^{2,3}$, Abdus Salam ${ }^{4}$ and Bibhuti Bhusan Kakoti ${ }^{2}$

\begin{abstract}
Background: Garcinia lanceifolia Roxb. has been used by many ethnic communities of Northeast India to mitigate various disorders like dyspepsia, ulcers, diabetes, etc. However, a robust scientific study on its antidiabetic and antiulcer potential is unavailable till date. The aim of this present study is to scientifically validate if the antidiabetic and antiulcer effects reported by the ethnic tribes of Assam has any scientific value or not. The effects were tested in adult Wistar albino rats using approved animal models for preclinical testing of pharmacological activities.

Results: The hydroalcoholic extract of the bark of Garcinia lanceifolia Roxb. was prepared and its $L_{50}$ was calculated. The $\mathrm{LD}_{50}$ was determined to be greater than $5000 \mathrm{mg} / \mathrm{kg}$ body weight. The extract at doses of $250 \mathrm{mg} /$ $\mathrm{kg}$ body weight and $500 \mathrm{mg} / \mathrm{kg}$ body weight was found to exhibit a very potent dose-dependent antidiabetic activity. The results were backed by a battery of test including analysis of serum levels of blood glucose, lipid profiles, in vivo antioxidant enzymes, and histopathological studies. Evidence of dose-dependent antiulcer activity of the extract was backed by robust scientific data. It was found that HAEGL induced a significant dose-dependent increase in the ulcer index in both alcohol-induced and acetic acid-induced ulcer models, which was evident from the macroscopic observation of the inner lining of the gastric mucosa and the histological evaluation of the extracted stomach.

Conclusion: The results suggested that the bark of Garcinia lanceifolia (Roxb.) has significant antidiabetic and antiulcer potential. Further studies with respect to the development herbal dosage forms and its safety evaluation are required.
\end{abstract}

Keywords: Garcinia lanceifolia, Antidiabetic, Antiulcer, Acute toxicity, Wistar albino rats

\section{Background}

Modern world is in great rush pushing everyone to deal with a magnetic and energetic life where each one compromising with their energy balance either knowing or unknowingly. The above circumstances help physiological systems to disturb its own metabolic homeostasis and enzyme balance. Consequences are not safe at all as these conditions leading the mankind into metabolic disorder especially diabetic condition, obesity, hypertension, and dyslipidemia $[1,2]$.

\footnotetext{
* Correspondence: nilutpalsharma3@gmail.com

'NETES Institute of Pharmaceutical Science, NEMCARE Group of Institutions,

Mirza, Kamrup, Guwahati, Assam 781125, India

2Department of Pharmaceutical Sciences, Dibrugarh University, Dibrugarh,

Assam 786004, India

Full list of author information is available at the end of the article
}

Diabetes is a metabolic worse condition where living cells are deprived of glucose for energy causing glucose accumulation [3] in blood stream. Insulin, secreting hormone from pancreatic $\beta$ cell, helps glucose molecule to enter into cell associated with cell surface glucose transporter to produce energy for living body in the form of adenosine triphosphate $[4,5]$. However, diabetic condition aggravate as a collective or individual result of inadequate insulin secretion and insulin resistance [6] toward cell surface insulin receptor. It is now listed among the leading five causes of death worldwide indicating the eye opening statistics from American Diabetes Association and World Health Organization (WHO) [7, 8]. On the other context, ulcer or peptic ulcer is a very common gastrointestinal (GI) disorder which affected 
more than $10 \%$ of the world's population characterized by damage of lower GI tract inner lining either by acid and/or pepsin with Helicobacter pylori [9] in the absence of them. Along with these conditions, continuous administration of non-steroidal anti-inflammatory drugs (NSAIDs), stress, smoking, and excessive alcohol consumption are some proven factors that erase the mucosal epithelium layer [10-12]. As collective of those patient faces severe burning sensation in lower abdomen with abdominal pain and passing blood with stool sometimes [9].

Pharmacological interventions are available for both the problems but being as synthetic chemicals, they target some other functions causing unwanted toxicities. Antidiabetic agents like biguanides, sulfonylureas, $\alpha-$ glucosidase inhibitors [13], PPAR- $\gamma$ agonists, SGLT-2 antagonist, and DPP-IV inhibitors, [6, 14, 15] are controlling the pandemic condition either in single mode or in combination but cardiac and hepatic tissues affected in most of the case. For treating peptic ulcer proton pump inhibitors (PPI), $\mathrm{H}_{2}$ receptor antagonists, antimuscarinics, sucralfate, and bismuth are employed but they are also having additive effects [16]. So these viewpoints urge the exploration of some herbal products as better and safe alternatives.

Garcinia lanceifolia Roxb [17, 18]. belonging to family Clusiaceae has been a lesser known plant in the pile of huge published literatures for days. In a recent study, Ghosh et al. [19] reported its antihyperglycemic potency of whole plant using the protocols of oral glucose tolerance test (OGTT). Other species of Garcinia are reported for antiulcer effect [12, 16, 20] so far with other pharmacological activities. In light of the above survey, an attempt was made to investigate and report the antidiabetic and antiulcerative potential of methanolic extract from Garcinia lanceifolia Roxb. bark. using adult Wistar albino rats. The physiological, anatomical, and genetic similarity of Wistar rats with humans and their ease of handling and maintenance make them an ideal choice for the testing of preclinical testing of biological activities.

The objective of this study was to a twofold one. Firstly, in one set of rodents, the antidiabetic activity of the plant was tested in streptozotocin induced diabetic model; and secondly, in another set, the antiulcer activity was tested using two different models, viz., alcohol-induced antiulcer model and acetic acid-induced ulcer model separately. Prior to that, the acute toxicity study was performed as per approved protocols, to calculate the $\mathrm{LD}_{50}$ of the extract.

\section{Methods}

\section{Animals}

Adult male Wistar Albino rats of uniform weight (180$250 \mathrm{~g}$ ) were used in this study, which were commercially purchased from the enlisted supplier of the University (M/S Chakraborty Enterprise, Kolkata, West Bengal, India). The animals were free to access food and potable water as they underwent acclimatization under laboratory conditions for 2 weeks prior to the experiment. All experiments were conducted during the day time (between 0900 and $1600 \mathrm{~h}$ ), after an overnight fasting period. During the entire experimental period, the animals were maintained as per the guidelines of the Guide for the Care and Use of Laboratory Animals, National Institutes of Health (NIH). The rats were hygienically maintained in polypropylene cages in an air-conditioned environment of $22-25{ }^{\circ} \mathrm{C}, 40-70 \%$ humidity with $12 \mathrm{~h}$ light-dark cycles, and ventilation of 15-21 air changes/h. The entire study was permitted by the Institutional Animal Ethics Committee (IAEC), Assam, and conducted by following the guidelines of Committee for the Purpose of Control and Supervision of Experiments on Animals (CPCSEA); with prior approval number IAEC/DU/60 dated 24/09/2013.

\section{Plant material and extraction}

The collection of the bark of Garcinia lanceifolia was done from the University campus and neighboring areas of Dibrugarh, Assam India in accordance to the Good Agricultural and Collection Practice (GACP) guidelines. Images of the plant and collected fresh bark are shown in Fig. 1. The plant herbarium was authenticated by Dr. A. A. Mao, Botanical Survey of India, Eastern Regional Centre, Shillong (Letter no.: BSI/ERC/2014/Plant identification/882. A herbarium specimen of the plant was submitted at the Pharmacognosy Research Lab of the Institute for further references. After proper cleaning of the collected bark, it was cut into smaller pieces and dried to constant weight. Thereafter, the dried bark were pulverized in a mechanical grinder and stored in hermetically sealed containers until extraction process commenced.

The hydroalcoholic extract of the stem bark of Garcinia lanceifolia (HAEGL) was prepared by using cold maceration process with $1000 \mathrm{~mL}$ of water:ethanol (80:20) mixture. The extracts were concentrated by distillation, followed by vacuum drying using a rotary evaporator. Preliminary phytochemical tests were carried out with all the extracts in order to evaluate for the presence of different phytochemical constituents.

\section{Chemicals}

All chemicals used in this assay were of analytical grade and obtained from reputed suppliers like SRL Sisco Research Laboratories Pvt. Ltd., Mumbai, India; Roche (Products) Pvt. Ltd., Bayer Diagnostics, Mumbai, India; Himedia Laboratory, Mumbai, India; Loba Chemie, Mumbai, India; Rankem Chemicals, Faridabad, India; 

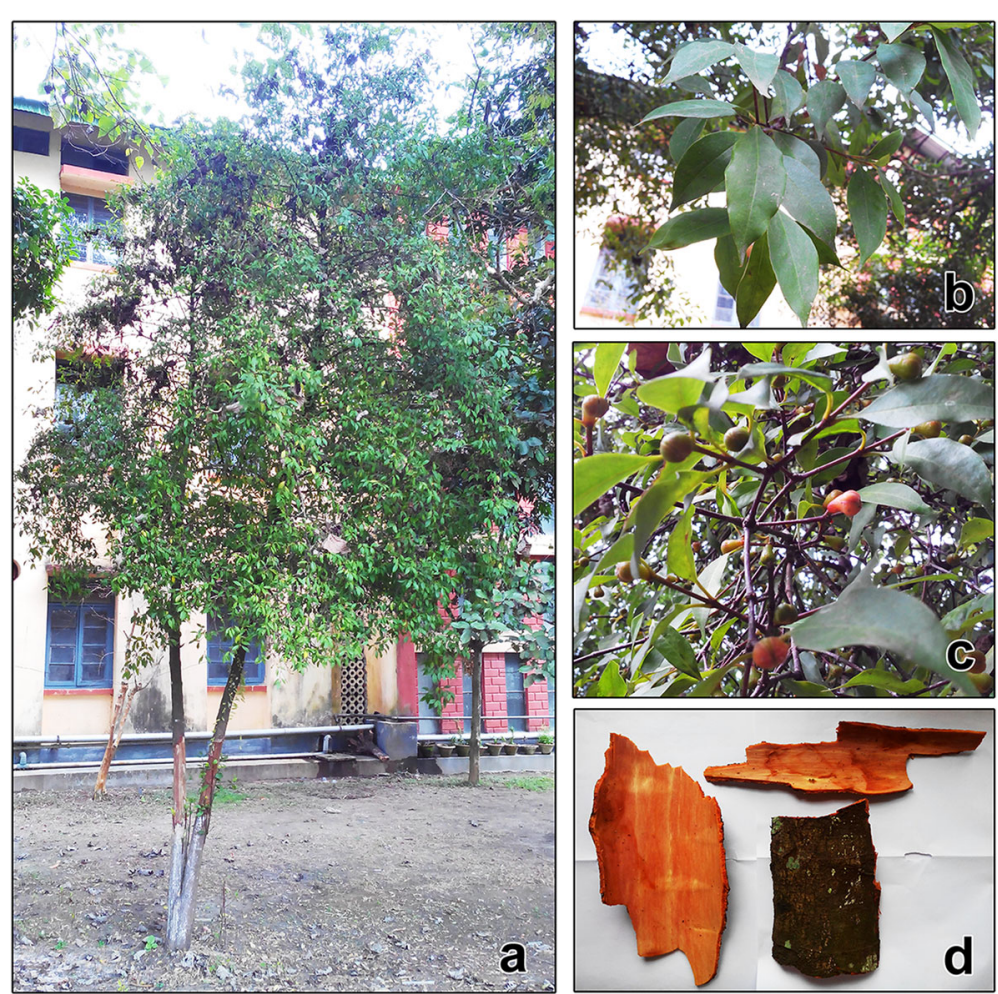

Fig. 1 Images of Garcinia lanceifolia plant. a Whole plant. b Leaves arrangement. c Young fruits. d Collected bark

Otto Chemie, Mumbai, India; SRL Sisco Research Laboratories, Mumbai, India; Spectrochem, Mumbai, India; and Beacon Diagnostics Pvt. Ltd; Gujarat, India.

\section{Acute toxicity and $\mathrm{LD}_{50}$ calculation of HAEGL}

To process the toxicological studies of HAEGL, a series of doses, viz; $175 \mathrm{mg} / \mathrm{kg}, 550 \mathrm{mg} / \mathrm{kg}, 1750 \mathrm{mg} / \mathrm{kg}, 5000$ $\mathrm{mg} / \mathrm{kg}$ body weight were used.

To obtain the $\mathrm{LD}_{50}$ of HAEGL, the experiments were planned according to the methods approved by the Organization for Economic Cooperation and Development (OECD). After acclimatization of the environment, rats were administered HAEGL with doses in the sequence listed previously by a single oral gavage. The highest dose limit of $5000 \mathrm{mg} / \mathrm{kg}$ for HAEGL was determined by subjecting to a limit test at $5000 \mathrm{mg} / \mathrm{kg}$, as per OECD guideline 425. Each dose was given to a single animal only. If the animal survived the current dose, the second animal received a consecutive higher dose. If the animal does not survive, the second animal received a lower dose. Since HAEGL did not show any toxicity reactions below the regulatory limit doses (i.e., $5000 \mathrm{mg}$ / $\mathrm{kg}$ ); hence, it was evaluated by a limit test of $5000 \mathrm{mg} /$ $\mathrm{kg}$. The $\mathrm{LD}_{50}$ and $95 \%$ profile likelihood (PL) of HAEGL were obtained by analyzing the experimental data using the AOT425 program (OECD guideline 425) [21-23].

\section{Antidiabetic assay}

\section{Oral glucose tolerance test}

Initial screening of the extract for the hypoglycemic activity was done in healthy rats by conducting oral glucose tolerance test (OGTT). The OGTT was performed for two different doses of HAEGL (250 and $500 \mathrm{mg} / \mathrm{kg}$ of bodyweight per orally) and blood glucose level was measured by one touch glucometer (ACCU-CHEK ${ }^{\oplus}$, Roche India Pvt. Ltd., Mumbai, India). The blood glucose levels were estimated at the intervals of 0th, 30th, 60th, 90th, and 120th min after the administration of extract [24].

\section{Induction of non-insulin dependent diabetes mellitus}

Following overnight fasting, type II diabetes was stimulated in the experimental animals by an intraperitoneal (i.p.) inoculation of streptozotocin (Spectrochem, Mumbai, India) dissolved in $0.1 \mathrm{M}$ cold citrate buffer $(\mathrm{pH}$ 4.5), at a dose of $65 \mathrm{mg} / \mathrm{kg}$ of bodyweight; followed 110 $\mathrm{mg} / \mathrm{kg}$ of nicotinamide via the i.p. route (Spectrochem, Mumbai, India). The control rats were administered with the vehicle alone. The induced rats were tested for the presence of elevated blood glucose levels after 7 days and the rats with moderate hyperglycemia (blood glucose range of above $250 \mathrm{mg} / \mathrm{dl}$ ) were utilized for the experiment [25]. 
Table 1 Results of limit test for HAEGL conducted using AOT425 Statistical Program

\begin{tabular}{|c|c|c|c|c|}
\hline Test sequence & Animal ID & Dose $(\mathrm{mg} / \mathrm{kg})$ & Short-term result & Long-term result \\
\hline 1 & HAEGL1 & 5000 & $\mathrm{O}$ & $\mathrm{O}$ \\
\hline 2 & HAEGL2 & 5000 & O & $\mathrm{O}$ \\
\hline 3 & HAEGL3 & 5000 & $x$ & $x$ \\
\hline 4 & HAEGL4 & 5000 & $\mathrm{O}$ & $\mathrm{O}$ \\
\hline \multicolumn{5}{|c|}{ Legend: $(X=$ died, $O=$ survived $)$} \\
\hline \multicolumn{5}{|c|}{ Summary of long term results } \\
\hline Dose & & Animals survived & Animals died & Total \\
\hline $5000 \mathrm{mg} / \mathrm{kg} \mathrm{bw}$ & & 3 & 1 & 4 \\
\hline
\end{tabular}

Statistical estimation suggested that the $\mathrm{LD}_{50}$ is greater than $5000 \mathrm{mg} / \mathrm{kg}$

\section{Experimental design}

The rats were segregated into five groups and for each group five animals were taken as follows:

Group 1: Normal control rats administered with 0.5\% carboxymethylcellulose $(\mathrm{CMC})$ vehicle $5 \mathrm{~mL} / \mathrm{kg}$ bodyweight per orally.

Group 2: Streptozotocin (STZ)-induced diabetic control rats.

Group 3: Diabetic control rats treated with HAEGL (250 $\mathrm{mg} / \mathrm{kg}$ body weight/day) dissolved in aqueous solution of $0.5 \%$ CMC per orally for 15 days.

Group 4: Diabetic control rats administered orally once a day for 15 days with HAEGL $(500 \mathrm{mg} / \mathrm{kg}$ body weight/ day) dissolved in aqueous solution of $0.5 \%$ CMC. Group 3 and 4 were served as test drug treated groups.

Group 5: Diabetic control rats treated orally once a day for 15 days with the standard drug metformin (Yarrow Chem Products, Mumbai, India) at a dose $10 \mathrm{mg} / \mathrm{kg}$ of bodyweight which served as standard control.
Blood was sampled from the tail vein of the overnight (12-15 h) fasted rats and fasting blood glucose levels along with the average body weights were closely monitored on 0th, 5th, 10th and 15th day. On the 15th day, all the animals underwent euthanasia via cervical dislocation under moderate anesthesia and evaluated for various biochemical parameters, histopathology and in vivo anti-oxidant status [26].

\section{Biochemical investigation}

Total cholesterol (TC), triglycerides (TG) in EDTA plasma, and aspartate transaminase (SGOT), alanine transaminase (SGPT), alkaline phosphatase (ALP) levels in serum were measured colorimetrically using specific kits (Beacon Diagnostics Pvt. Ltd; Gujarat, India) as per the manufacturers' instructions.

\section{Histological studies}

After euthanizing the animals, the pancreas of the experimental animals were collected and analyzed for

Table 2 Results of acute toxicity studies ( $\left(D_{50}\right.$ calculation) of HAEGL conducted using AOT425 Statistical Program

\begin{tabular}{|c|c|c|c|c|}
\hline Test sequence & Animal ID & Dose (mg/kg) & Short-term result & Long-term result \\
\hline 1 & HAEGL1 & 175 & $\mathrm{O}$ & O \\
\hline 2 & HAEGL2 & 550 & O & O \\
\hline 3 & HAEGL3 & 1750 & O & O \\
\hline 4 & HAEGL4 & 5000 & $x$ & $x$ \\
\hline 5 & HAEGL5 & 1750 & $\mathrm{O}$ & O \\
\hline 6 & HAEGL6 & 5000 & $\mathrm{O}$ & O \\
\hline 7 & HAEGL7 & 5000 & O & O \\
\hline 8 & HAEGL8 & 5000 & O & $x$ \\
\hline \multicolumn{5}{|c|}{ Legend: $(X=$ died, $O=$ survived $)$} \\
\hline \multicolumn{5}{|c|}{ Summary of long term results } \\
\hline Dose (mg/kg bw) & & Animals survived & Animals died & Total \\
\hline 175 & & 1 & 0 & 1 \\
\hline 550 & & 1 & 0 & 1 \\
\hline 1750 & & 2 & 0 & 2 \\
\hline 5000 & & 2 & 2 & 4 \\
\hline All doses & & 6 & 2 & 8 \\
\hline
\end{tabular}


Table 3 Effect of HAEGL on oral glucose tolerance test in Wistar albino rats

\begin{tabular}{llllll}
\hline Animal group & $\mathbf{0}$ min & $\mathbf{3 0}$ min & $\mathbf{6 0}$ min & $\mathbf{9 0}$ min & 120 min \\
\hline Normal control & $77.0 \pm 0.54$ & $141.4 \pm 0.92$ & $152.6 \pm 1.12$ & $162.8 \pm 0.96$ & $181.6 \pm 1.43$ \\
HAEGL $(250 \mathrm{mg} / \mathrm{kg})$ & $78.2 \pm 1.31$ & $103.2 \pm 0.91^{* *}$ & $100.8 \pm 1.49^{* *}$ & $94.0 \pm 0.54^{* *}$ & $83.82 \pm 2.83^{* *}$ \\
HAEGL $(500 \mathrm{mg} / \mathrm{kg})$ & $79.0 \pm 0.83$ & $100.6 \pm 1.47^{* *}$ & $101.8 \pm 2.31^{* *}$ & $41.6 \pm 0.97^{* *}$ & $81.0 \pm 0.54^{* *}$ \\
\hline
\end{tabular}

Values are expressed as mean \pm SEM $(n=5)$, statistical significance: ${ }^{*} p<0.05,{ }^{* *} p<0.01$, compared with normal control group

histological changes. The skin samples were fixed in a fixative mixture of fixative (picric acid, formaldehyde $40 \%$, and glacial acetic acid) for $24 \mathrm{~h}$ and thereafter embedded in paraffin with a melting point of $55-57{ }^{\circ} \mathrm{C}$. Sections of $6 \mu \mathrm{m}$ were obtained and stained with hematoxylin and eosin (H\&E) stain to assess any structural alterations in the pancreas. All stained specimens were observed using optical light microscope and photographed using a camera.

\section{In vivo antioxidant assay}

About $400 \mathrm{mg}$ of liver tissue was samples from each experimental animal subject, rinsed in normal saline, and blotted with filter paper. The tissues were then homogenized in $1.15 \%$ potassium chloride $(\mathrm{KCl})$ and centrifuged at $1200 \mathrm{rpm}$ at $40{ }^{\circ} \mathrm{C}$ for $10 \mathrm{~min}$. The supernatant was collected which were again centrifuged at $10,000 \mathrm{rpm}$ at $40{ }^{\circ} \mathrm{C}$ for $10 \mathrm{~min}$. Again the supernatant were collected and centrifuged at $14,000 \mathrm{rpm}$ for $60 \mathrm{~min}$ at $40{ }^{\circ} \mathrm{C}$. The microsomal fraction were taken, suspended in $\mathrm{KCl}$, and stored at $-20{ }^{\circ} \mathrm{C}$.

Thereafter, the processed samples were analyzed separately to determine the levels of lipid peroxidation (LPO), reduced glutathione (GSH), and catalase activity (CAT) as per methods described earlier, with trivial modifications [27-29].

\section{Antiulcer assay}

\section{Absolute alcohol induced ulcer model}

The study was carried out as per the methods described by Umamaheswari et al. 2007 and Deore et al. 2011 [12, 30]. The rats were divided into five groups and for each group five animals were taken as follows:
Group 1: Normal control rats administered with $0.5 \%$ carboxymethylcellulose $(\mathrm{CMC})$ vehicle $5 \mathrm{~mL} / \mathrm{kg}$ bodyweight per orally.

Group 2: Rats with ethanol-induced ulcers (1 mL absolute alcohol per orally).

Group 3: Ulcer-induced rats administered orally once a day for 5 days with HAEGL $(250 \mathrm{mg} / \mathrm{kg}$ body weight /day) dissolved in aqueous solution of 0.5\% CMC. Group 4: Ulcer-induced rats administered orally once a day for 5 days with HAEGL ( $500 \mathrm{mg} / \mathrm{kg}$ body weight/ day) dissolved in aqueous solution of $0.5 \% \mathrm{CMC}$.

Group 3 and 4 were served as test drug treated groups. Group 5: Ulcer-induced rats treated orally once a day for 5 days with the standard drug ranitidine (Yarrow Chem Products, Mumbai, India) at a dose $50 \mathrm{mg} / \mathrm{kg}$ of bodyweight which served as standard control.

On the 6th day, the animals were sacrificed by cervical dislocation under mild anesthesia and stomach was incised along the greater curvature and examined for ulcers. The ulcer index was counted, by taking into account the product of length and width of the ulcers observed in the glandular section of the stomach (square millimeters per rat). The summation of the lengths $(\mathrm{mm})$ of all lesions for each stomach sample salvaged was termed as the ulcer index (UI)

$$
\mathrm{UI}=(n \text { lesion } I)+(n \text { lesion } I I)+(n \text { lesion } I I I)
$$

where UI = ulcer index; $\mathrm{I}$ = presence single, submucosal, punctiform hemorrhages along with of edema and hyperemia; II = presence of hemorrhagic submucosal lesions with minor erosions; III = evidence of profound ulcers with invasive lesions and erosions.

Table 4 The deviation of body weight of the animals treated with HAEGL during 15 days of treatment

\begin{tabular}{lllll}
\hline Animal group & Day $\mathbf{0}$ & Day $\mathbf{5}$ & Day $\mathbf{1 0}$ & Day 15 \\
\hline Normal control & $190.6 \pm 2.80 \# \#$ & $191.6 \pm 2.80 \# \#$ & $192.6 \pm 0.39 \# \#$ & $195.6 \pm 2.20 \# \#$ \\
Diabetic control & $182.4 \pm 1.47 \#$ & $181.2 \pm 1.59^{*}$ & $176.6 \pm 2.33^{* *}$ & $174.4 \pm 2.20^{* *}$ \\
HAEGL $(250 \mathrm{mg} / \mathrm{kg})$ & $196.2 \pm 4.12 \# \#$ & $193.00 \pm 3.39 \# \#$ & $192.6 \pm 3.62 \# \#$ & $195.8 \pm 4.32 \# \#$ \\
HAEGL $(500 \mathrm{mg} / \mathrm{kg})$ & $179.2 \pm 1.55^{*}$ & $176.4 \pm 1.12^{* *}$ & $177.20 \pm 1.15^{* *}$ & $179.00 \pm 1.87^{* *}$ \\
Standard & $170.60 \pm 2.80^{* *}$ & $171.00 \pm 3.67^{* *}$ & $174.00 \pm 4.00^{* *}$ & $174.8 \pm 4.30^{* *}$ \\
\hline
\end{tabular}

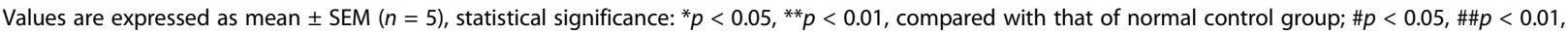
compared with standard group 
Table 5 The effect of HAEGL on fasting blood glucose level on streptozotocin-induced diabetic rats during 15 days of treatment

\begin{tabular}{lllll}
\hline Treatment & Day $\mathbf{0}$ & Day $\mathbf{5}$ & Day $\mathbf{1 0}$ & Day 15 \\
\hline Normal control & $92.53 \pm 0.44$ & $102.00 \pm 0.54^{\# \#}$ & $102.60 \pm 1.07^{\# \#}$ & $96.40 \pm 0.67^{\# \#}$ \\
Diabetic control & $242.6 \pm 1.12^{* *}$ & $264.80 \pm 1.46^{* \# \#}$ & $270.00 \pm 2.23^{* \# \# \#}$ & $270.00 \pm 0.54^{* * \# \#}$ \\
HAEGL $(250 \mathrm{mg} / \mathrm{kg})$ & $244.80 \pm 1.28^{* *}$ & $177.40 \pm 1.12^{* * \# \#}$ & $173.80 \pm 1.59^{* * \# \#}$ & $135.20 \pm 1.46^{* * \# \#}$ \\
HAEGL $(500 \mathrm{mg} / \mathrm{kg})$ & $241.40 \pm 1.10^{* *}$ & $160.80 \pm 1.85^{* *}$ & $132.00 \pm 0.89^{* * \# \#}$ & $123.80 \pm 2.03^{* * \# \#}$ \\
Standard drug & $240.00 \pm 2.73^{* *}$ & $164.00 \pm 1.87^{* *}$ & $132.60 \pm 1.12^{* *}$ & $113.20 \pm 1.20^{* *}$ \\
\hline
\end{tabular}

Values are mean \pm SEM $(n=5)$, statistical significance: ${ }^{*} p<0.05,{ }^{* *} p<0.01$, compared with normal control group; \#p $<0.05$, \#\#p $<0.01$, compared with standard group

The percentage inhibition was estimated by utilizing the following formula;

$$
\text { \%inhibition }=\left(\frac{U I_{\text {control }}-U I_{\text {treated }}}{U I_{\text {control }}}\right) \times 100
$$

\section{Acetic acid induced ulcer model}

The rats were segregated into five groups and for each group five animals were taken as follows:

Group 1: Normal control rats administered with 0.5\% carboxymethylcellulose (CMC) vehicle $5 \mathrm{~mL} / \mathrm{kg}$ bodyweight per orally.

Group 2: Rats with acetic acid-induced ulcers (by injection of $0.05 \mathrm{ml}$ of $10 \%$ acetic acid into the subserosal layer present in the glandular region of the anterior barrage of the stomach via a midline gastric incision performed under light anesthesia).

Group 3: Ulcer-induced rats administered orally once a day for 20 days with HAEGL (250 mg/kg body weight /day) dissolved in aqueous solution of 0.5\% CMC.

Group 4: Ulcer-induced rats administered orally once a day for 20 days with HAEGL (500 mg/kg body weight/ day) dissolved in aqueous solution of $0.5 \% \mathrm{CMC}$. Groups 3 and 4 were served as test drug-treated groups.

Group 5: Ulcer-induced rats treated orally once a day for 20 days with the standard drug famotidine (Yarrow Chem Products, Mumbai, India) at a dose $20 \mathrm{mg} / \mathrm{kg}$ of bodyweight which served as standard control.
All treatments were administered orally 1 day postsurgery for 20 days, and on the 21st day all the animals underwent euthanasia by cervical dislocation under moderate anesthesia, stomachs were salvaged, and the healing progression of the ulcers were evaluated. Gastric lesions were assessed by investigating the inner gastric plane using a dissecting-binocular microscope. Thereafter, the ulcer area $\left(\mathrm{mm}^{2}\right)$ and curative rate (\%) were determined [30]. Thereafter, the stomach were immersed in $10 \%$ formalin and processed for histopathological evaluation. If presence of ulcerated tissue was detected, the center part of the damaged tissue was taken and dissected in half along the long diameter. In case of undamaged tissue, the sections from the basal part were taken.

\section{Statistical analysis}

All statistical analysis was performed by utilizing the GraphPad Prism software version 5.0 (GraphPad Software, La Jolla, CA, US). One-way ANOVA followed by various post-hoc tests was used to analyze the difference among multiple dosage groups. All values are expressed as mean \pm SEM. A $p<0.05$ value, evaluated at $95 \%$ level of confidence, was considered as statistically significant; unless otherwise indicated in the results.

\section{Results}

Acute toxicity and $\mathrm{LD}_{50}$ calculation of HAEGL

For the limit test of HAEGL, the Acute Oral Toxicity (OECD Test Guideline 425)-AOT425 Statistical Program was used and each animal after exposure to the

Table 6 The effect of HAEGL on biochemical parameters in streptozotocin-induced diabetic rats on the $15^{\text {th }}$ day of treatment

\begin{tabular}{llllll}
\hline Treatment & Cholesterol $(\mathbf{m g} / \mathbf{d l})$ & Triglyceride $(\mathbf{m g} / \mathbf{d l})$ & SGOT & SGPT & ALP \\
\hline Normal control & $158.2 \pm 0.91^{\# \#}$ & $207.6 \pm 1.12^{\# \#}$ & $52.60 \pm 1.12$ & $40.80 \pm 0.96^{\# \#}$ & $104.20 \pm 0.37^{\# \#}$ \\
Diabetic control & $228.2 \pm 0.91^{* * \# \#}$ & $300.2 \pm 0.91^{\# \# *}$ & $105.00 \pm 2.2^{* * \# \#}$ & $82.40 \pm 0.74^{* * \# \#}$ & $172.60 \pm 1.12^{* * \# \#}$ \\
HAEGL $(250 \mathrm{mg} / \mathrm{kg})$ & $207.4 \pm 1.12^{* * \# \#}$ & $256 \pm 1.87^{\# \# * *}$ & $72.80 \pm 0.96^{* * \# \#}$ & $65.80 \pm 0.96^{* * \# \#}$ & $133.2 \pm 1.20^{* * \# \#}$ \\
HAEGL $(500 \mathrm{mg} / \mathrm{kg})$ & $177.8 \pm 1.28^{* * \# \#}$ & $237.4 \pm 1.12^{* *}$ & $54.00 \pm 1.34^{\# \#}$ & $52.40 \pm 1.07^{* * \# \#}$ & $125.20 \pm 1.46^{* *}$ \\
Standard drug & $165.8 \pm 0.96^{* *}$ & $236.4 \pm 1.56^{* *}$ & $51.80 \pm 0.91$ & $47.40 \pm 0.74^{* *}$ & $120.40 \pm 0.74^{* *}$ \\
\hline
\end{tabular}

Values are mean $\pm \operatorname{SEM}(n=5)$, statistical significance: ${ }^{*} p<0.05,{ }^{* *} p<0.01$, compared with normal control group; \#p $<0.05$, \#\#p $<0.01$, compared with standard group 


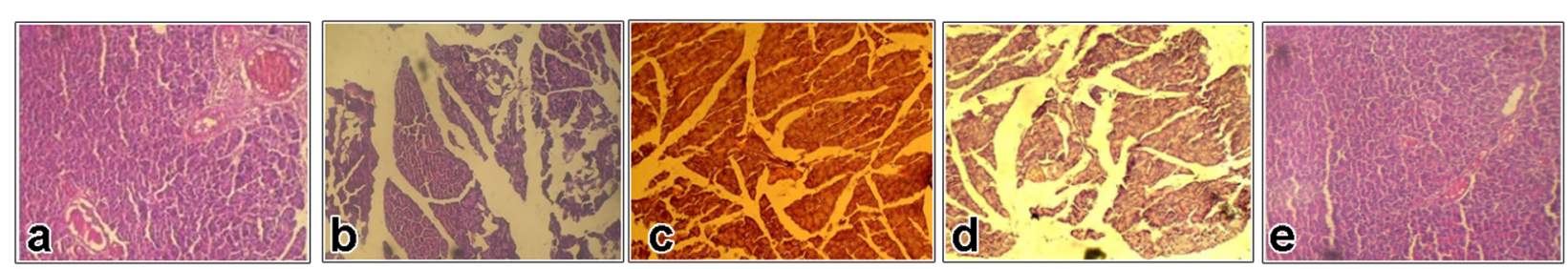

Fig. 2 Representative images for histopathological evaluation of pancreas of Wistar albino rats subjected to STZ-induced diabetic model at $\times 100$ magnification. a Normal control group. b Diabetic control. c HAEGL $(250 \mathrm{mg} / \mathrm{kg})$. d HAEGL $(500 \mathrm{mg} / \mathrm{kg})$. e Standard

hypothesized limit dose $(5000 \mathrm{mg} / \mathrm{kg}$ body weight $)$ and the results as listed in Table 1 . Thereafter, mortality in each unique animal was observed and recorded. $\mathrm{LD}_{50}$ value of the test sample was hence calculated. The limit test was found to be complete when 3 animals survived the hypothesized limit dose administered in the study.

Thereafter, for the estimation of acute toxicity, the dose progression suggested by AOT425 Statistical Program was used. Only one animal was exposed to one dose followed by observations for signs of toxicity or death. The test was found to be complete when three animals survived at the limit dose as calculated in the $\mathrm{LD}_{50}$ calculation study previously. The test results are displayed in Table 2.

In both the experiments, symptoms exhibited by the experimental animals after exposure to the test formulations were observed during for a 14-day period. During this period, all the animals that survived did not show any signs of toxicity; like loss of appetite, diarrhea, and vomiting or passive behavior, hypopnea, tremor, and arching of back. It was found that HAEGL is non-toxic as per the Hodge and Sterner scale and AOT425 Statistical Software with a $\mathrm{LD}_{50}$ value of $5000 \mathrm{mg} / \mathrm{kg}$ body weight and 95\% profile likelihood (PL) of 2045 to > 20000.

\section{Antidiabetic assay \\ Oral glucose tolerance test}

In oral glucose tolerance test (OGTT), HAEGL, from 30 min onwards exhibited significant decrease in plasma glucose levels (Table 3). Initially, the induction of diabetes was ascertained by the presence of a high fasting blood glucose levels in the experimental rats. It was evident from the study that the experimental animals were responsive toward the particular OGTT protocols.

\section{Analysis of serum glucose and body weight levels}

The effects of different doses $(250 \mathrm{mg} / \mathrm{kg}$ and $500 \mathrm{mg} / \mathrm{kg}$ of bodyweight) of the HAEGL on the fasting blood level were investigated in the streptozotocin-induced diabetic Wistar albino rats using metformin hydrochloride as standard drug (10 mg/kg of bodyweight). The divergence of body weights and study reports of oral glucose tolerance test (OGTT) of the animals were noted in Tables 4 and 5 respectively, which were noted on the 0th, 5th, 10th, and 15th day of treatment.

\section{Biochemical investigation}

The levels of TC, TG in EDTA plasma and SGOT, SGPT, ALP levels in serum were evaluated on the 15th day; i.e., the final day of treatment using HAEGL. It was observed that both the doses of HAEGL were able to mitigate the deviation in the biochemical markers which were affected in streptozotocin-induced diabetic Wistar albino rats. The results are tabulated in Table 6 .

\section{Histological studies}

The results of the histopathological studies on the pancreas of the streptozotocin-induced diabetic Wistar albino rats are shown in Fig. 2. The pancreas plays a major role

Table 7 Effect of HAEGL on liver in vivo antioxidant enzymes in streptozotocin-induced diabetic rats on the 15th day of treatment

\begin{tabular}{|c|c|c|c|}
\hline Treatment & $\begin{array}{l}\text { Lipid peroxidase ( } \mathrm{nM} \text { of } \mathrm{MDA} / \mathrm{mg} \text { of } \\
\text { protein) }\end{array}$ & $\begin{array}{l}\text { Glutathione ( } \mathrm{nM} / \mathrm{mg} \text { of } \\
\text { protein) }\end{array}$ & $\begin{array}{l}\text { Catalase ( } \mathrm{nM} \text { of } \mathrm{H}_{2} \mathrm{O}_{2} \text { decomposed } / \mathrm{min} / \mathrm{mg} \text { of } \\
\text { protein) }\end{array}$ \\
\hline Normal control & $15.41 \pm 0.24^{\# \#}$ & $50.80 \pm 0.80^{\# \#}$ & $14.20 \pm 0.80^{\# \#}$ \\
\hline Diabetic control & $35.60 \pm 0.40^{* * \# \#}$ & $23.80 \pm 1.02^{* * \# \#}$ & $5.60 \pm 0.40^{* * \# \#}$ \\
\hline $\begin{array}{l}\text { HAEGL }(250 \mathrm{mg} / \\
\mathrm{kg})\end{array}$ & $25.20 \pm 0.48^{* * \#}$ & $31.80 \pm 0.73^{* *}$ & $5.40 \pm 0.40^{* * \# \#}$ \\
\hline $\begin{array}{l}\text { HAEGL }(500 \mathrm{mg} / \\
\mathrm{kg})\end{array}$ & $23.20 \pm 0.80^{* * \# \#}$ & $42.20 \pm 0.97^{* * \# \#}$ & $7.60 \pm 0.24^{* *}$ \\
\hline Standard drug & $27.40 \pm 0.40^{* *}$ & $35.20 \pm 0.80^{* *}$ & $8.40 \pm 0.24^{* *}$ \\
\hline
\end{tabular}

Values are mean \pm SEM $(n=5)$, statistical significance: ${ }^{*} p<0.05,{ }^{* *} p<0.01$, compared with normal control group; \#p $<0.05$, \#\#p<0.01, compared with standard group 
Table 8 Effect of HAEGL on alcohol-induced and acetic acid-induced gastric ulcer on rats

\begin{tabular}{lll}
\hline Treatment & Alcohol-induced gastric ulcer index & Acetic acid-induced gastric ulcer index \\
\hline Normal control & - & - \\
Ulcer control & $34.67 \pm 2.60$ & $42.00 \pm 1.73$ \\
HAEGL $(250 \mathrm{mg} / \mathrm{kg})$ & $12.67 \pm 1.76^{* *}$ & $16.67 \pm 0.88^{* *}$ \\
HAEGL $(500 \mathrm{mg} / \mathrm{kg})$ & $11.33 \pm 1.20^{* *}$ & $14.67 \pm 1.45^{* * *}$ \\
Standard drug & $4.00 \pm 0.58^{* * *}$ & $4.67 \pm 0.88^{* * *}$ \\
\hline
\end{tabular}

Values are mean \pm SEM $(n=3)$, statistical significance: ${ }^{*} p<0.05,{ }^{* *} p<0.01$, when compared with ulcer control group

in the regulation of blood sugar levels due to the secretion of insulin by the $\beta$ cells of the islets of Langerhans. It was observed that the various detrimental effects observed in the sections of the pancreas extracted from diabetic rats were significantly ameliorated in the HAEGL-treated groups. Effects like shrunken cell size, architectural damage, absence of islets cells, fatty layer degradation, loss of cellular integrity, irregular gap junctions, and lymphocyte infiltration were evident in the diabetic control group. Whereas, in the treated groups, these effects were very nominal and the sections were very much comparable to the standard drug treated group. A normal control group was also observed for comparative analysis.

\section{In vivo antioxidant assay}

Oxidative stress induced by streptozotocin was evaluated by analyzing various in vivo markers. LPO, GSH, and CAT enzymes were estimated in all the experimental groups and the results are displayed in Table 7. It was observed that due to occurrence of diabetes, there was a significant increase LPO levels along with depletion of GSH and CAT enzymes in the diabetic control group. These effects were markedly decreased in the HAEGLtreated groups, and the results were found to be

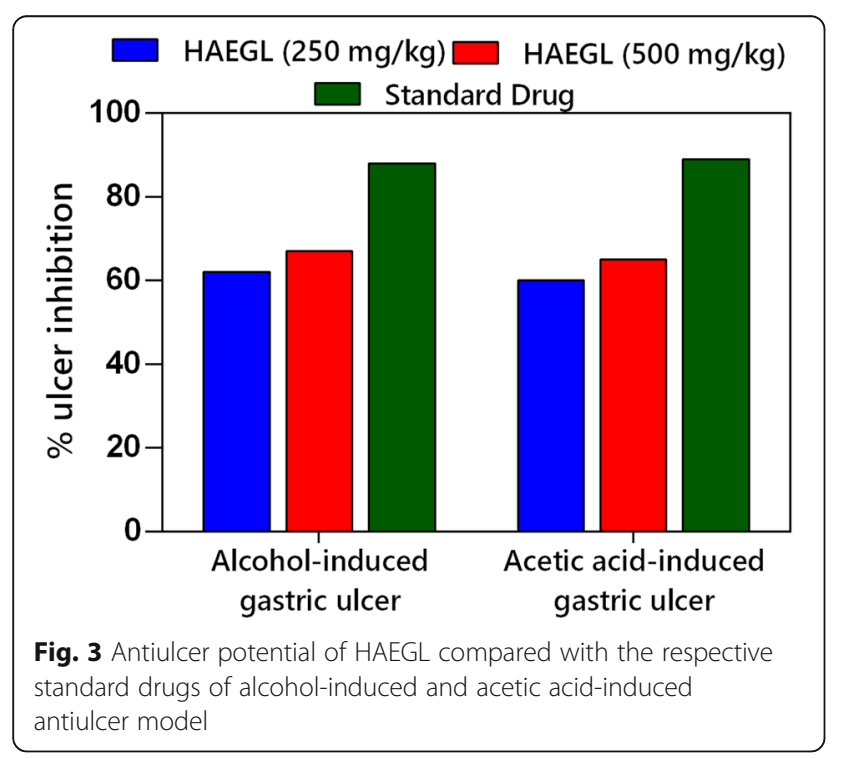

statistically significant when compared with the diabetic and normal control groups.

\section{Antiulcer assay}

Both the studies conducted in the absolute alcoholinduced ulcer model and the acetic acid-induced ulcer model confirmed that HAEGL had a good potential for reduction of gastric ulcer in Wistar rats (see Table 8). In the absolute alcohol-induced ulcer model, rats treated with HAEGL at doses of $250 \mathrm{mg} / \mathrm{kg}$ body weight and $500 \mathrm{mg} / \mathrm{kg}$ body weight showed a significant reduction in the ulcer index $(p<0.01)$. After 5 days of treatment, HAEGL (250 mg/kg) and HAEGL (500 mg/ $\mathrm{kg}$ ) showed a reduction of $62 \%$ and $67 \%$ respectively, while the standard ranitidine showed a protection index of $88 \%$ (Fig. 3). Similarly in the acetic acid-induced ulcer model, it was observed that HAEGL (250 $\mathrm{mg} / \mathrm{kg})$ and HAEGL (500 $\mathrm{mg} / \mathrm{kg}$ ) showed a reduction of $60 \%$ and $65 \%$ respectively, while the standard famotidine showed a protection index of $89 \%$.

The results of the histopathological studies, on the inner lining of the extracted stomachs of the experimental animals, are shown in Fig. 4. Fig. 4a-e displays a representative image of each of the groups of the absolute alcohol induced ulcer model and Fig. $3 \mathrm{f}-\mathrm{j}$ shows the results of the acetic acid induced ulcer model. It was observed that the detrimental effects of both the ulcer models like loss of gland architecture, erosion of the epithelial layer, edema, infiltration by inflammatory cells, etc. were effectively ameliorated in the HAEGL-treated groups. The results were comparable with the standard groups.

\section{Discussion}

Garcinia lanceifolia is a well-known medicinal plant used extensively in the northeastern part of India. It is also used in edible culinary preparations and eaten as a fruit. Traditionally, this plant is known to have many medicinal properties like antiulcer, anthelmintic, and anti-inflammatory properties. It is known to contain many bioactive agents like xanthones, bioflavonoids, benzophenones, benzoquinones, and triterpenes which contribute to its beneficial effects [31, 32]. The present study is aimed at the exploration of antidiabetic and 

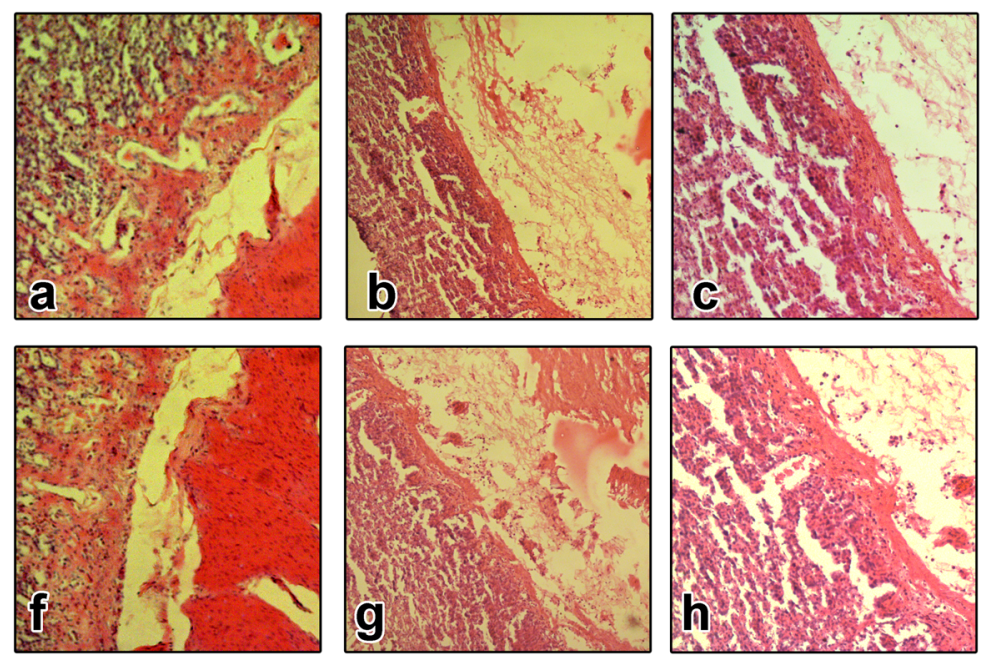
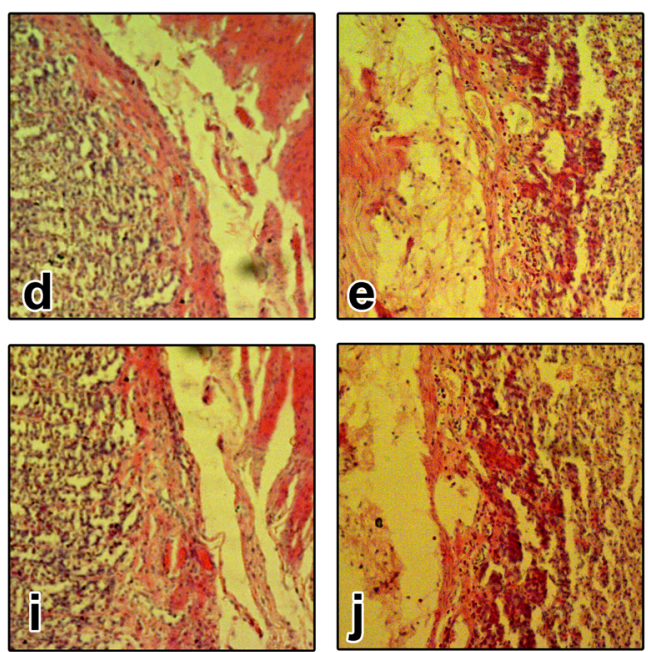

Fig. 4 Representative images for histopathological evaluation of inner gastric surface of Wistar albino rats subjected to alcohol-induced (plate 'a' to ' $\mathbf{e}$ ') and acetic acid-induced antiulcer model (plate ' $\mathbf{f}$ ' to ' $\mathbf{j}$ ') at $\times 100$ magnification. a Normal control group. b Diabetic control. c HAEGL (250 $\mathrm{mg} / \mathrm{kg})$. d HAEGL $(500 \mathrm{mg} / \mathrm{kg})$. e Standard

antiulcer potential of G. lanceifolia bark extracts. These traditionally claimed effects were tested using scientifically backed animal models and established protocols.

The acute toxicity studies of HAEGL were tested using Acute Oral Toxicity (OECD Test Guideline 425)AOT425 Statistical Program. It was found that the $\mathrm{LD}_{50}$ value of HAEGL was $5000 \mathrm{mg} / \mathrm{kg}$ body weight. There were no visible signs of treatment related adverse effects or mortality in the experimental animals. Changes in behavior or metabolism were not experiential in short period $(24 \mathrm{~h})$ and long period observations (14 days). The antidiabetic potential of HAEGL was tested using streptozotocin-induced diabetic model. It was observed that the animals treated with HAEGL displayed a dosedependent decrease in the serum blood glucose levels along with significant improvements in other symptoms related to diabetes. Hepatic overproduction and decreased utilization of glucose in the body tissues is a characteristic feature of diabetes. These symptoms were found to be ameliorated in the experimental animals treated with $500 \mathrm{mg} / \mathrm{kg}$ body weight of HAEGL, at the end of the 15-day treatment period. The blood glucose readings were taken on the 0th, 5th, 10th, and 15th days and HAEGL-treated groups observed significantly lower blood sugar as compared to the diabetic control group (Table 5). The results were not as pronounced as the standard drug (metformin) treated groups but were comparable. HAEGL may be inducing these effects by increasing the effects of insulin in plasma by increasing either the pancreatic secretion of insulin from the existing beta cells or by its release from the bound form [25]. Levels of cholesterol and triglycerides which were found to be increased in cases of diabetic rats were also control in the HAEGL-treated groups in a dose-dependent manner. Loss of body weight which is a characteristic feature of diabetes was also found to be improved in a dose-dependent manner [33, 34]. STZ is known to produce free radicals in the body and oxidative stress has shown to play a major role in the pathogenesis of types I and II diabetes by causing pancreatic injury. As a result, antioxidants from plant material may play a vital role in the amelioration of these effects [35, 36]. Our study demonstrated that treatment with HAEGL significantly improved the serum levels of SGOT, SGPT, and ALP along with improvements of the in vivo antioxidant enzymes. This may be due to the presence of phenolic compounds, flavonoids, and triterpenoids in HAEGL, as reported in our previously published articles [18, 31]. Histopathological examination of the sections of pancreas extracted from the experimental animals revealed that the gross changes in histopathological architecture along with other structural damage to the cells that were observed in the diabetic rats were not present in the HAEGLtreated groups. The cytoprotective action that was observed in the HAEGL-treated groups was minute and suggested that this protective action may have resulted in the improvement of the diabetic conditions of the rats.

The antiulcer activity of HAEGL was tested using two different animal models; viz. absolute alcohol-induced ulcer model, and the acetic acid-induced ulcer model. The results suggested that HAEGL was able to significantly reduce the ulcer caused in both the experimental models. Ethanol-induced gastric ulcers are widely used in antiulcer 
animal model. Metabolism of ethanol in the body releases superoxide anion and hydroperoxy free radicals, which are found to be a part of the mechanism of acute as well as chronic ulceration in the gastric mucosa. Acetic acidinduced chronic ulcer model produces gastric lesions restricted to the glandular stomach which are identical to chronic gastric ulcers of human. Reactive nitrogen species (RNS) have been found to be involved in the gastric mucosal damage [30]. The antioxidant content of G. lanceifolia have been reported earlier [18], which may be the postulated reason for the antiulcer activity of this plant.

\section{Conclusion}

These studies suggested that the traditional use of $G$. lanceifolia as an antiulcer and antidiabetic agent is backed by scientific data now. It may be hypothesized that continuous consumption of this plant may result in reduced occurrences of diabetes and gastric ulcer in humans. However, further studies regarding the development of a drug which contains these activities are required in the future. Moreover, studies related to the isolation of active constituents and its molecular pathway studies are also warranted.

\section{Abbreviations \\ ATP: Adenosine triphosphate; WHO: World Health Organization; NSAI Ds: Non-steroidal anti-inflammatory drugs; OGTT: Oral glucose tolerance test; IAEC: Institutional Animal Ethics Committee; CPCSEA: Committee for the Purpose of Control and Supervision of Experiments on Animals; HAEG L: Hydroalcoholic extract of the stem bark of Garcinia lanceifolia; OECD: Organization for Economic Cooperation and Development; LD: Lethal dose; i.p.: Intraperitoneal; CMC: Carboxymethylcellulose; STZ: Streptozotocin; mg: Milligram; kg: Kilogram; h: Hours; TC: Total cholesterol; TG: Triglycerides; SGOT: Aspartate transaminase; SGPT: Alanine transaminase; ALP: Alkaline phosphatase; H\&E: Hematoxylin and eosin; min: Minutes; rpm: Rotations per minute; LPO: Lipid peroxidation; GSH: Reduced glutathione; CAT: Catalase activity; Ul: Ulcer index; $\mathrm{mm}$ : Millimeter}

\section{Acknowledgements}

The authors are thankful to Department of Pharmaceutical Sciences, Dibrugarh University, India, for providing the research facilities for this work. The authors gratefully acknowledge the support of Dr. Giriraj Kusre, Associate Professor, Dept. of Anatomy, Assam Medical College for his immense help and support in conducting a part of the research work in his special facility of Diagnostic Genetic Lab (CFDMGD), Dept, of Anatomy, Assam Medical College. The authors also extend their deepest gratitude to Dr. Hirak Das, Assistant Professor, Anatomy, AMC and P.I. of CFDMGD; Dr. Pritanu Deb Baruah, Assistant Professor, Anatomy, AMC and Mr. Rupjyoti Lahon, Lab Technician, CFDMGD; for their guidance and support.

\section{Details of plant sources}

Garcinia lanceifolia (Roxb.): Neighboring areas of University Campus (Voucher specimen No: DU/NSB/01.

\section{Plant authentication}

The plant herbarium was authenticated by Dr. A. A. Mao, Botanical Survey of India, Eastern Regional Centre, Shillong (Letter no.: BSI/ERC/2014/Plant identification/882. A herbarium specimen of the plant was submitted at the Pharmacognosy Research Lab of the Institute for further references.

\section{Authors' contributions}

All authors have read and approved the manuscript. NSB designed and executed the work, plant collection, extraction, and animal experiments; PSB conducted the serum analysis and extraction of animal organs; AS participated in the histopathological studies; BBK edited the manuscript and gave final permission for publication.

\section{Funding}

The entire work was financially supported by AICTE (All India Council of Technical Education), Research Promotion Scheme (RPS) 2011, Grant no. 8023/RIB/RPS-10/(NER)/2011-12.

\section{Availability of data and materials}

All data and material are available upon request.

\section{Ethics approval and consent to participate}

The experimental procedures relating to the animals were authorized by CPCSEA (Committee for the Purpose of Control and Supervision of Experiments on Animals); vide approval number IAEC/DU/60 dated 24/09/ 2013.

\section{Consent for publication \\ Not applicable.}

\section{Competing interests}

The authors declare that they have no competing interests.

\section{Author details}

${ }^{1}$ NETES Institute of Pharmaceutical Science, NEMCARE Group of Institutions, Mirza, Kamrup, Guwahati, Assam 781125, India. ${ }^{2}$ Department of Pharmaceutical Sciences, Dibrugarh University, Dibrugarh, Assam 786004, India. ${ }^{3}$ School of Pharmacy, Graphic Era Hill University, Bell Road, Clement Town, Dehradun, Uttakhand 248002, India. ${ }^{4}$ Gupta College of Technological Sciences, Ashram More, G.T. Road, Asansol, West Bengal 713301, India.

Received: 23 April 2020 Accepted: 31 August 2020

Published online: 03 November 2020

\section{References}

1. Pradeepa R, Surendar J, Indulekha K, Chella S, Anjana RM, Mohan V (2016) Prevalence of metabolic syndrome and its association with coronary artery disease among an urban elderly South Indian population (CURES- 145). J Assoc Phys India 64(5):20-25

2. Prasad DS, Kabir Z, Dash AK, Das BC (2012) Prevalence and risk factors for metabolic syndrome in Asian Indians: a community study from urban Eastern India. J Cardiovasc Dis Res 3:204-211. https://doi.org/10.4103/09753583.98895

3. Greiner EF, Guppy M, Brand K (1994) Glucose is essential for proliferation and the glycolytic enzyme induction that provokes a transition to glycolytic energy production. J Biol Chem 269:31484-31490

4. Kahn CR, White MF (1988) The insulin receptor and the molecular mechanism of insulin action. J Clin Invest 82:1151-1156. https://doi.org/10. 1172/JCl113711

5. Gould GW, Holman GD (1993) The glucose transporter family: structure, function and tissue-specific expression. Biochem J 295(2):329-341. https:// doi.org/10.1042/bj2950329

6. Bairy PS, Shankar B, Das A (2015) Diabetes mellitus and antidiabetics with reference to alpha glucosidase inhibitors. J Biomed Pharm Res 4(6):10-16

7. Roglic G (2016) WHO Global report on diabetes: a summary. Int J Non Commun Dis 1:3-8

8. American Diabetes Association (2017) Statistics about diabetes. In: CDC National Diabetes Statistics Report. Available via https://www.diabetes.org/ resources/statistics/statistics-about-diabetes.

9. Vimala G, Gricilda SF (2014) A review on antiulcer activity of few Indian medicinal plants. Int J Microbiol 2014:1-14. https://doi.org/10.1155/2014/ 519590

10. Malfertheiner P, Chan FK, McColl KEL (2009) Peptic ulcer disease. Lancet 374: 1449-1461. https://doi.org/10.1016/S0140-6736(09)60938-7

11. Sagar V, Ahamed RN (1999) Gastric mucosal cellular changes induced by Indomethacin (NSAID) in male albino rats. Indian J Exp Biol 37(04):365-369

12. Deore AB, Sapakal VD, Dashputre NL, Naikwade NS (2011) Antiulcer activity of Garcinia indica linn fruit rinds. J Appl Pharm Sci 1(5):151-154

13. Bairy PS, Das A, Nainwal LM, Mohanta TK, Kumawat MK, Mohapatra PK, Parida P (2016) Design, synthesis and anti-diabetic activity of some novel 
xanthone derivatives targeting a-glucosidase. Bangladesh J Pharmacol 11: 308-318. https://doi.org/10.3329/bjp.v11i2.25851

14. Asche C, LaFleur J, Conner C (2011) A review of diabetes treatment adherence and the association with clinical and economic outcomes. Clin Ther 33(1):74-109. https://doi.org/10.1016/j.clinthera.2011.01.019

15. Miller BR, Nguyen $\mathrm{H}$, Hu CJ-H, Lin C, Nguyen QT (2014) New and emerging drugs and targets for type 2 diabetes: reviewing the evidence. Am Heal drug benefits 7(8):452-463

16. Onasanwo SA, Singh N, Olaleye SB, Palit G (2011) Anti-ulcerogenic and proton pump $(\mathrm{H}+, \mathrm{K}+$ ATPase) inhibitory activity of Kolaviron from Garcinia kola Heckel in rodents. Indian J Exp Biol 49(6):461-468

17. Bora NS, Kakoti BB, Gogoi B (2014) Study on antibacterial activity of the bark of Garcinia lanceifolia Roxb. Int Sch Res Not 2014:1-3. https://doi.org/10. 1155/2014/784579

18. Bairy PS, Bora NS, Kakoti B, Das A, Nainwal L, Gogoi B (2016) Preliminary phytochemical screening, in-vitro antioxidant activity, total polyphenolic and flavonoid content of Garcinia lanceifolia Roxb. and Citrus maxima (Burm.) Merr. J Appl Pharm Sci 6(9):133-139. https://doi.org/10.7324/JAPS. 2016.60920

19. Ghosh A, Banik S, Amin MN, Ahmed J (2018) Evaluation of antinociceptive, antihyperglycemic, and membrane stabilizing activities of Garcinia lancifolia Roxb. J Tradit Complement Med 8(2):303-307. https://doi.org/10.1016/j. jtcme.2017.04.009

20. Obolskiy D, Pischel I, Siriwatanametanon N, Heinrich M (2009) Garcinia mangostana L.: a phytochemical and pharmacological review. Phyther Res 23(8):1047-1065. https://doi.org/10.1002/ptr.2730

21. Viswanatha GLS, Vaidya SK, Ramesh C, Krishnadas N, Rangappa S (2010) Antioxidant and antimutagenic activities of bark extract of Terminalia arjuna. Asian Pac J Trop Med 3(12):965-970. https://doi.org/10.1016/S19957645(11)60010-2

22. Chen Z, Meng H, Xing G, Chen C, Zhao Y, Jia G, Wang T, Yuan H, Ye C, Zhao F, Chai Z, Zhu C, Fang X, Ma B, Wan L (2006) Acute toxicological effects of copper nanoparticles in vivo. Toxicol Lett 163(2):109-120. https:// doi.org/10.1016/j.toxlet.2005.10.003

23. Whitehead A, Stallard N (2004) Opportunities for reduction in acute toxicity testing via improved design. Altern Lab Anim 32(Suppl 2):73-80. https://doi. org/10.1177/026119290403202s15

24. Bonner-Weir S (1988) Morphological evidence for pancreatic polarity of $\beta$ cell within islets of langerhans. Diabetes 37(5):616-621. https://doi.org/10. 2337/diab.37.5.616

25. Shirwaikar A, Rajendran K, Dinesh Kumar C, Bodla R (2004) Antidiabetic activity of aqueous leaf extract of Annona squamosa in streptozotocinnicotinamide type 2 diabetic rats. J Ethnopharmacol 91(1):171-175. https:// doi.org/10.1016/j.jep.2003.12.017

26. Gandhi GR, Sasikumar P (2012) Antidiabetic effect of Merremia emarginata Burm. F. in streptozotocin induced diabetic rats. Asian Pac J Trop Biomed 2(4):281-286. https://doi.org/10.1016/S2221-1691(12)60023-9

27. Ohkawa H, Ohishi N, Yagi K (1979) Assay for lipid peroxides in animal tissues by thiobarbituric acid reaction. Anal Biochem 95(2):351-358. https://doi.org/ 10.1016/0003-2697(79)90738-3

28. Mulder TPJ, Manni JJ, Roelofs HMJ, Peters WHM, Wiersma A (1995) Glutathione S-transferases and glutathione in human head and neck cancer. Carcinogenesis 16(3):619-624. https://doi.org/10.1093/carcin/16.3.619

29. Bora NS, Mazumder B, Mandal S, Patowary P, Goyary D, Chattopadhyay P, Dwivedi SK (2019) Amelioration of UV radiation-induced photoaging by a combinational sunscreen formulation via aversion of oxidative collagen degradation and promotion of TGF- $\beta$-Smad-mediated collagen production. Eur J Pharm Sci 127:261-275. https://doi.org/10.1016/j.ejps.2018.11.004

30. Umamaheswari M, Asokkumar K, Rathidevi R, Sivashanmugam AT, Subhadradevi V, Ravi TK (2007) Antiulcer and in vitro antioxidant activities of Jasminum grandiflorum L. J Ethnopharmacol 110(3):464-470. https://doi.org/ 10.1016/j.jep.2006.10.017

31. Bora NS, Kakoti BB, Yadav P, Gogoi B, Borah S (2017) Phyto-physicochemical , acute and subacute toxicity studies of Garcinia lanceifolia Roxb .- - a rare ethnomedicinal plant of Assam , India. Indian J Nat Prod Resour 8(4):360369

32. Bora NS, Kakoti BB, Bairy PS, Gogoi B (2014) Garcinia lanceifolia Roxb ; an endemic medicinal plant of assam relieves pain and delays nociceptive response : an assay for its analgesic and anti-inflammatory activity. Int J Pharm Sci Drug Res 6:216-219
33. Chase HP (1976) Juvenile diabetes mellitus and serum lipids and lipoprotein levels. Arch Pediatr Adolesc Med 130:1113. https://doi.org/10.1001/archpedi. 1976.02120110075010

34. Swanston-Flatt SK, Day C, Bailey CJ, Flatt PR (1990) Traditional plant treatments for diabetes. Studies in normal and streptozotocin diabetic mice. Diabetologia 33:462-464. https://doi.org/10.1007/BF00405106

35. Baynes JW (1991) Role of oxidative stress in development of complications in diabetes. Diabetes 40(4):405-412. https://doi.org/10.2337/diab.40.4.405

36. Halliwell B, Gutteridge JMC (1985) Free radicals in biology and medicine. FEBS Lett 188(1):346. https://doi.org/10.1016/0014-5793(85)80903-0

\section{Publisher's Note}

Springer Nature remains neutral with regard to jurisdictional claims in published maps and institutional affiliations.

\section{Submit your manuscript to a SpringerOpen ${ }^{\circ}$ journal and benefit from:}

- Convenient online submission

- Rigorous peer review

- Open access: articles freely available online

- High visibility within the field

- Retaining the copyright to your article

Submit your next manuscript at $\boldsymbol{\nabla}$ springeropen.com 